\title{
Optimal Location and Sizing of UPQC for Improving Power System Quality
}

\author{
Khadija Al Balushi \\ International Maritime College Oman \\ Suhar Port Falaj Al Qabail, Suhar OM,Oman \\ khadijalbalushi8@gmail.com
}

\begin{abstract}
Unified Power Quality Conditioner (UPQC) is an electrical device with series and shunt converters that are connected continuously and it mainly concerns resolving the Power Quality (PQ) issues related to current and voltage harmonics. The presented work focuses on the enhancement of power quality by optimal allocation and sizing of UPQC devices under a variety of operating states. Consequently, the "Salp Swarm-Crow Search algorithm (SS-CSA)" is deployed in the presented work for determining the optimal sizing and location of UPQC by resolving the power quality. At last, analysis is carried out for proving the superiority of the deployed scheme over other traditional schemes in terms of cost analysis and convergence analysis.
\end{abstract}

Keywords: UPQC Device; Power Quality; Optimal Location; Sizing; SS-CSA.

\begin{tabular}{ll}
\multicolumn{2}{l}{ Nomenclature } \\
\hline Abbreviations & Descriptions \\
\hline APF & Active Power Filter \\
ABC & Artificial Bee Colony \\
COA & Cuckoo Optimization Algorithm \\
DE & Differential Evolution \\
GA & Genetic Algorithm \\
HICA-PS & Hybrid Imperialist Competitive Algorithm-Pattern Search \\
MOPSO & Multi-objective Particle Swarm Optimisation \\
PCC & Point of Common Coupling \\
PAC & Phase Angle Control \\
PQ & Power Quality \\
THD & Total Harmonic Distortion \\
SS-CSA & Salp Swarm-Crow Search algorithm \\
UPQC & Unified Power Quality Conditioner \\
VSM & Voltage Stability Margin \\
VSI & Voltage Source Inverters \\
\hline
\end{tabular}

\section{Introduction}

Currently, the accomplishment of PQ and preservation of voltage are achieving substantial awareness in distributed systems for overcoming the fluctuations in voltage, flicker, harmonics, etc. Consequently, for sustaining stability, FACTS devices were developed that resolves numerous issues and thereby offers a superior power quality. FACTS [1] [2] devices are broadly employed in power systems for enhancing PQ of networks such as UPQC and so on [3] [4] [5]. The UPQC [6] [7] is a sort of sophisticated power device and it is a combination of both shunt with series APF. It aids in eradicating the issues that occur due to unbalances, distortions \& harmonics and accordingly assists in achieving a superior power system quality. UPQC [8] [9] is an adaptable device and it comprises the capacity to resolve the problems, which take place because of voltage harmonics and current.

UPQC [10] [11] involves 2 VSI and compensators that help in enhancing voltage sags, flickers, and unbalances and harmonics [12] [13]. "The series portion includes voltage to sustain the balanced and 
distortion-free system, at the PCC; whereas, the shunt part of UPQC [14] passes the current to PCC, such that the incoming power to PCC bus is maintained sinusoidal". The majority of the UPQC analysis focuses on 2 bus networks [15], which do not incur more time utilization.

UPQC for optimum allocation and sizing have to reduce a certain level of voltage drop if necessary [2]. The key function of UPQC is to recompense for issues, like, "sags unbalance harmonics and flicker". In addition, the allotment of capacitors is regarded as a major issue and as a result, it is crucial to find out the accurate location of capacitors in a much proficient manner, by which the loss can be reduced and voltage profile can be developed.

The main contribution of this work concentrates on the improvement of power quality by optimal allocation and sizing of UPQC devices under a variety of operating states. As a result, the SS-CSA is deployed in the developed method to determine the optimal sizing and location of UPQC to solve the power quality.

The work is organized as follows: The reviews are given in section 2 and section 3 delineates the enhancement of power quality in UPQC: basic principles. The optimal allocation of UPQC via the SSCSA approach is described in section 4. The results and conclusion are specified in Section 5 and 6 respectively.

\section{Literature Review}

In 2016, Majid et al. [1] have suggested a method for optimal placement of UPFC; for which load shedding coordination Moreover, the HICA-PS model was deployed in this work, where ICA was optimally tuned using the pattern search scheme. Further, tests were carried that demonstrated the efficiency of the presented method over the other existing approaches.

In 2016, Jayanti and Goswami [2] have introduced an allocation method for UPQC that involves the concept of optimization. In this context, the optimal allotment was done based on COA. In addition, the development of the offered method was analyzed in terms of varied metrics such as THD, harmonics, and so on. Finally, the developed approach was evaluated over traditional models and its advantage was confirmed.

In 2018, Lakshmi and Ganguly [3] have designed a UPQC model, which concurrently optimized the energy losses and PVHC of distribution systems. Consequently, MOPSO was deployed for obtaining the optimum solution. The developed model integrated the Pareto-approximation set, which included several trade-off solutions and energy loss. Eventually, simulation outcomes have revealed that the developed model has diminished the energy loss with enlarged PV values.

In 2014, Ganguly et al. [4] have carried out a methodical examination on UPQC- PAC in radial distribution networks. Consequently, the impacts of UPQC allocations were examined which resulted in considerable development of VSM and power loss minimization. In addition, negligible power loss was obtained by means of the presented scheme when computed over the traditional models.

In 2014, Ganguly [5] had presented a PSO-oriented model, which maintained an optimal allocation of UPQC. As per the adopted model, the optimal location, reactive power, and optimal modelling constraints were evaluated by decreasing the power loss, range of nodes, and UPQC rate. Eventually, the supremacy of the adopted model was proved with a diverse examination.

\section{Enhancement of Power Quality in UPQC: Basic Principles}

\subsection{Functions of UPQC}

The basic operations of UPQC consist of series and shunt inverters. Usually, the highest voltage sag is minimized for the series inverter for facilitating the magnitude of infused voltage $V_{i v}$. During voltage drops and normal states, the level of the source voltage is denoted as $\mathrm{V}^{\mathrm{s}}=\mathrm{V}^{\mathrm{s} 0}$ and $\mathrm{V}^{\mathrm{s}}=\mathrm{kV}^{\mathrm{s} 0}$, in which $\mathrm{k}_{\mathrm{sag}}=(1-\mathrm{k})$ and at specific states, load voltage $\mathrm{V}^{1}=\mathrm{V}^{\mathrm{s} 0}=\mathrm{V}^{\mathrm{s}}$. The voltage injection (series) necessary for lessening the $\mathrm{k}_{\mathrm{sag}}$ p.u. level of voltage sag is revealed by Eq. (1). The diagram of UPQC is exposed by Fig. 1.

$$
\begin{aligned}
\mathrm{V}_{\mathrm{iv}} & =\sqrt{\left(\left(\mathrm{V}^{1}\right)^{2}+\left(\mathrm{kV}^{\mathrm{s} 0}\right)^{2}-2 \mathrm{~V}^{1}\left(\mathrm{kV}^{\mathrm{s} 0}\right) \cos \delta\right.} \\
& =\mathrm{V}^{\mathrm{s}} \sqrt{1+\mathrm{k}^{2}-2 \mathrm{k} \cos \delta}
\end{aligned}
$$




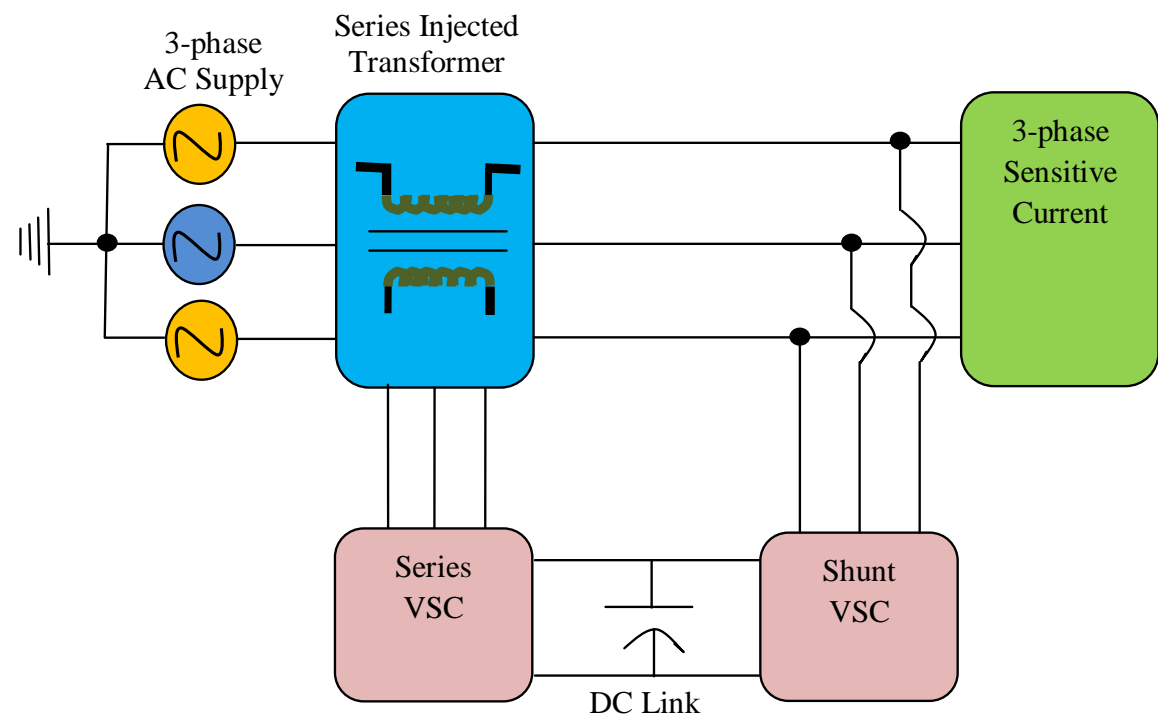

Fig. 1. Diagrammati representation of $U P Q C$

The amount of active power essential for the load in a lossless UPQC is revealed via active power obtained by the source as kI ${ }^{\mathrm{S}} \mathrm{V}^{\mathrm{s}}=\mathrm{I}^{1} \mathrm{~V}^{1} \cos \phi$, which forms the source current as shown in Eq. (2). In Eq. (2), $I^{1}$ signifies the load current and $I^{s}$ point out the balanced source end current.

$$
I^{\mathrm{s}}=\mathrm{I}^{1} \cos \phi / \mathrm{k}
$$

Based on Eq. (1) and Eq. (2), the VA ratings for the series inverter are attained as shown in Eq. (3). The reactive and active power is portrayed by Eq. (5) and (4), in which $\theta^{\mathrm{iv}}=180^{\circ}-\tan ^{-1}(\sin \delta / 1-\cos \delta)$.

$$
\begin{aligned}
& \mathrm{S}^{\mathrm{iv}}=\mathrm{I}^{\mathrm{s}} \mathrm{V}^{\mathrm{iv}}=\mathrm{I}^{\mathrm{l}} \mathrm{V}^{\mathrm{s}} \cos \phi \sqrt{1+\mathrm{k}^{2}-2 \mathrm{k} \cos \delta / \mathrm{k}} \\
& \mathrm{P}^{\mathrm{iv}}=\mathrm{S}^{\mathrm{iv}} \cos \theta^{\mathrm{iv}} \\
& \mathrm{Q}^{\mathrm{iv}}=\mathrm{S}^{\mathrm{iv}} \cos \theta^{\mathrm{iv}}
\end{aligned}
$$

Eq. (6) denotes the compensating current $\mathrm{I}^{\mathrm{st}}$ using shunt inverter. Eq. (7) and (8) signify the presence of nonlinear load, and the harmonic existing in load end is balanced by shunt inverter, here ( $\mathrm{I}_{\text {dis }}^{\text {st }}$ and $\mathrm{I}_{\mathrm{dis}}^{\mathrm{l}}$ ), $\left(\mathrm{I}_{\mathrm{f}}^{\mathrm{st}}\right.$ and $\left.\mathrm{I}_{\mathrm{f}}^{1}\right)$ and $\left(\mathrm{THD}^{\mathrm{st}}\right.$ and $\left.\mathrm{THD}^{1}\right)$ signify the distortion component, fundamental element and THD for shunt inverter and load current.

$$
\begin{aligned}
& \mathrm{I}^{\mathrm{st}}=\sqrt{\left(\mathrm{I}^{\mathrm{s}}\right)^{2}+\left(\mathrm{I}^{1}\right)^{2}-2 \mathrm{I}^{\mathrm{s}} \mathrm{I}^{1} \cos (\phi-\delta)} \\
&=\mathrm{I}^{1} \sqrt{\frac{\cos ^{2} \phi}{\mathrm{k}^{2}}+1-\cos (\phi-\delta) \frac{2 \cos \phi}{\mathrm{k}}} \\
& \mathrm{I}_{\mathrm{dis}}^{1}=\mathrm{I}_{\mathrm{dis}}^{\mathrm{st}} \\
& \mathrm{THD}^{1} \mathrm{I}_{\mathrm{f}}^{1}=\mathrm{THD}^{\mathrm{st}} \mathrm{I}_{\mathrm{f}}^{\mathrm{st}}
\end{aligned}
$$

The r.m.s for current is indicated by Eq. (9) and Eq. (10) indicates the VA rating of shunt inverter.

$$
\begin{aligned}
\mathrm{I}^{\mathrm{st}} & =\mathrm{I}_{\mathrm{f}}^{\mathrm{st}} \sqrt{1+\left(\mathrm{THD}^{\mathrm{st}}\right)^{2}} \\
& =\mathrm{I}_{\mathrm{f}}^{1} \sqrt{\frac{\cos ^{2} \phi}{\mathrm{k}^{2}}+1-\cos (\phi-\delta) \frac{2 \cos \phi}{\mathrm{k}}+\left(\mathrm{THD}^{1}\right)^{2}} \\
\mathrm{~S}^{\mathrm{st}} & =\mathrm{V}^{\mathrm{s}} \mathrm{I}^{\mathrm{st}} \\
& =\mathrm{V}^{\mathrm{s}} \mathrm{I}_{\mathrm{f}}^{1} \sqrt{1+\cos ^{2} \phi / \mathrm{k}^{2}-2 \cos \phi \cos (\phi-\delta) / \mathrm{k}+\left(\mathrm{THD}^{1}\right)^{2}}
\end{aligned}
$$

Eq. (11) and (12) portray the active and reactive power attained by shunt inverter, in which $\theta^{\text {st }}=180^{\circ}-\tan ^{-1}\{\cos (\phi-\delta)-\cos \phi / \sin (\phi-\delta)\}+90^{\circ}-\delta$.

$$
\begin{aligned}
& \mathrm{P}^{\mathrm{st}}=\mathrm{S}^{\mathrm{st}} \cos \theta^{\mathrm{st}} \\
& \mathrm{Q}^{\mathrm{st}}=\mathrm{S}^{\mathrm{st}} \cos \theta^{\mathrm{st}} \\
& \mathrm{Q}^{\mathrm{UPQC}}=\mathrm{Q}^{\mathrm{iv}}+\mathrm{Q}^{\mathrm{st}}
\end{aligned}
$$

The total reactive power offered by UPQC is shown in Eq. (13). 


\subsection{Equality and Inequality Constraints}

The vital parameters that cause an impact on UPQC [2] are specified below.

Equality Constraints: The active and reactive power compensation is exposed by Eq. (14) and (15), here $\mathrm{Q}^{\mathrm{G}}$ and $\mathrm{P}^{\mathrm{G}}$ ie specifies the reactive and active power injected at ie, $\mathrm{Q}^{\mathrm{D}^{\mathrm{ie}}}$ and $\mathrm{P}^{\mathrm{D}^{\mathrm{ie}}}$ signify the necessities of reactive and active power in the system and $b^{\text {kie }}$ specifies the susceptance.

$$
\begin{aligned}
& \mathrm{P}^{\mathrm{G}^{\mathrm{ie}}}-\mathrm{P}^{\mathrm{D}^{\mathrm{ie}}}-\sum_{\mathrm{k}=1}^{\mathrm{N}^{1}} \mathrm{~g} \operatorname{kie}\left\{\left(\mathrm{V}^{\mathrm{ie}}\right)^{2}+\left(\mathrm{V}^{\mathrm{je}}\right)^{2}-2 \mathrm{~V}^{\mathrm{ie}} \mathrm{V}^{\mathrm{je}} \cos \left(\delta^{\mathrm{ie}}-\delta^{\mathrm{je}}\right)\right\}=0 \\
& \mathrm{Q}^{\mathrm{G}^{\mathrm{ie}}}-\mathrm{Q}^{\mathrm{D}^{\mathrm{ie}}}-\sum_{\mathrm{k}=1}^{\mathrm{N}^{1}} \mathrm{~b}^{\mathrm{kie}}\left\{\left(\mathrm{V}^{\mathrm{ie}}\right)^{2}+\left(\mathrm{V}^{\mathrm{je}}\right)^{2}-2 \mathrm{~V}^{\mathrm{ie}} \mathrm{V}^{\mathrm{je}} \sin \left(\delta^{\mathrm{ie}}-\delta^{\mathrm{je}}\right)\right\}=0
\end{aligned}
$$

Inequality Constraints: It portrays the capacity and functional range and it includes 3 factors as described below.

Line Flow Limit: It depicts the high power transfer ability via allocated transmission line with predetermined parameters as shown in Eq. (16), which $\mathrm{S}^{\mathrm{k}^{\mathrm{max}}}$ signifies the higher power flow value in $\mathrm{k}^{\text {th }}$ line.

$$
\mathrm{S}^{\mathrm{k}} \leq \mathrm{S}^{\mathrm{k}^{\max }}
$$

Bus Voltage Limits: It consists of an unbalance limit of node voltage as well as a magnitude limit of voltage. Eq. (17) corresponds to the limit criterion of "3-phase node voltage magnitude", in which $\mathrm{V}^{\mathrm{min}}$ and $\mathrm{V}^{\max }$ refers to minimal and maximal values.

$$
\mathrm{V}^{\min }<\mathrm{V}<\mathrm{V}^{\max }
$$

Eq. (18) represents a 3-phase voltage unbalance limit criterion, in which $\mathrm{Vu}^{\max }$ refers to the satisfactory value for voltage unbalances.

$$
\mathrm{Vu} \leq \mathrm{Vu}^{\max }
$$

Harmonic Limits: It consists of individual voltage THD limits and voltage harmonic limits. Eq. (19) represents the voltage THD limits, in which $\mathrm{THD}^{\mathrm{max}}$ refer to the maximal THD value.

$$
\mathrm{THD}^{\mathrm{V}} \leq \mathrm{THD}^{\max }
$$

The limits of voltage harmonics are shown by Eq. (20), where $\mathrm{V}^{\mathrm{h}^{\mathrm{max}}}$ refers to the maximum individual harmonic limit.

$$
\mathrm{V}^{\mathrm{h}} \leq \mathrm{V}^{\mathrm{h}}{ }^{\max }
$$

\section{OPtimal allocation of UPQC via SS-CSA Approach}

\subsection{Objective Model}

The proposed work focuses on the improvement of $\mathrm{PQ}$, which could be attained by localizing and sizing the UPQC device optimally. Eq. (21) demonstrates the objective function that defines the optimal allocation of UPQC, which is considered as a cost minimization function. In this work, Eq. (22) reveals the UPQC ${ }^{\text {COST }}$ in Eq. (21), in which Or stand for the UPQC's operating level in MVAr,

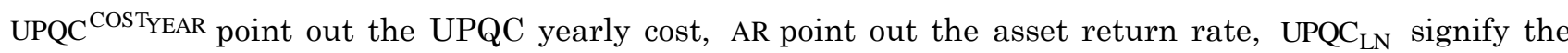
durability of UPQC. In addition, Eq. (23) represents the UPQC loss(Lo), wherein Oc $\mathrm{k}_{\mathrm{k}}$ point at the conductance of $\mathrm{k}^{\text {th }}$ line associated with $\mathrm{i}$ and $\mathrm{j}$ buses and $\delta_{\mathrm{j}}$ and $\delta_{\mathrm{i}}$ point out the voltage angle of $\mathrm{j}$ and ibuses. The VSI metrics are computed as in Eq. (24) that lies among 0.9 to 1.1, or else penalty is provided, here $\kappa$ describes a constant, $\mathrm{V}^{\mathrm{e}}$ point out the voltage magnitude for $\mathrm{e}^{\text {th }}$ bus.

$$
\begin{aligned}
& \mathrm{Obj}_{1}=\min \left\{\mathrm{UPQC}^{\mathrm{COST}}+\mathrm{Lo}+\mathrm{VS}\right\} \\
& \mathrm{UPQC}^{\operatorname{COST}}(\mathrm{US}(\$ / \mathrm{kVAr}))=0.0003 \mathrm{Or}^{2}-0.2691 \mathrm{Or}+188.22 \\
& \mathrm{UPQC}^{\operatorname{COST} \mathrm{YEAR}}=\mathrm{UPQC}^{\mathrm{COST}} \frac{(1-\mathrm{AR})^{\mathrm{UPQC}_{\mathrm{LN}} \times \mathrm{AR}}}{(1+\mathrm{AR})^{\mathrm{UPQC}_{\mathrm{LN}}-1}} \\
& \mathrm{Lo}=\sum_{\mathrm{k}=1}^{\mathrm{N}_{\mathrm{l}}} \mathrm{Lo}_{\mathrm{k}}=\sum_{\mathrm{k}=1}^{\mathrm{N}_{\mathrm{l}}} \mathrm{Oc}_{\mathrm{k}}\left\{\mathrm{V}_{\mathrm{i}}^{2}+\mathrm{V}_{\mathrm{j}}^{2}-2 \mathrm{~V}_{\mathrm{i}} \mathrm{V}_{\mathrm{j}} \cos \left(\delta_{\mathrm{i}}-\delta_{\mathrm{j}}\right)\right\} \\
& \mathrm{VSI}=\left\{\begin{array}{lc}
1 & \text { if } \quad \mathrm{V}^{\min } \leq \mathrm{V}^{\mathrm{e}} \leq \mathrm{V}^{\max } \\
\exp \left(\kappa\left|1-\mathrm{V}^{\mathrm{e}}\right|\right) & \text { otherwise }
\end{array}\right\}
\end{aligned}
$$




\subsection{Solution Encoding}

For attaining optimal localizing and sizing of UPQC, the location and size of the IEEE 33 bus system are given as solutions for encoding. For UPQC, $\operatorname{PTN}_{\mathrm{i}}, \mathrm{i}=1,2, \ldots, \mathrm{n}$ (bus line position) and $\mathrm{n}=33$ pointing out IEEE 33 buses and $\mathrm{SIZ}_{\mathrm{N}}$ signify UPQC size with limits between -10 to 10. Fig. 2 shows the solution encoding for optimal sizing and placement of UPQC.

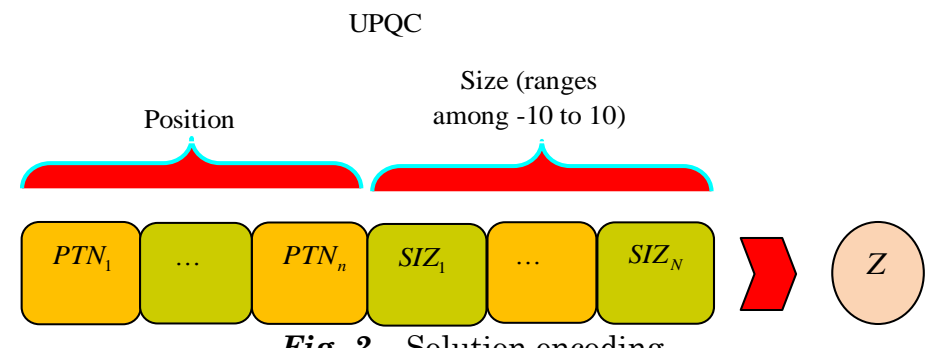

Fig. 2. Solution encoding

\subsection{SS- CSA Algorithm}

CSA algorithm depicts the intellectual characteristics of crow [9].

Step 1: Initialization: At first, the population of crow and its position in solution space are arbitrarily initialized as shown in Eq. (25), in which, $C_{i}^{j}$ points out the $j^{\text {th }}$ memory of $i^{\text {th }}$ crow.

$$
\mathrm{C}=\left\{\mathrm{C}_{\mathrm{i}}^{\mathrm{j}}\right\}
$$

Step 2: Fitness estimation: Following the allocation of values for the solution space in a random manner, the fitness of every solution is computed based on Eq. (21).

Step 3: Position update: The crow's position in the solution space is modified by memory update as shown in Eq. (26), in which $\mathrm{f}_{\mathrm{i}}(\mathrm{t})$ point out the flight length and $\mathrm{C}_{\mathrm{i}}^{\mathrm{j}}(\mathrm{t})$ symbolize the memory of $\mathrm{i}^{\text {th }}$ crow at iteration $\mathrm{t}$.

$$
C_{i}^{j}(t+1)=C_{i}^{j}(t)+q_{i} \times f_{i}(t) \times\left(a_{i}^{j}(t)-C_{i}^{j}(t)\right)
$$

In Eq. (26), $q_{i}$ refers to the arbitrary integer and $a_{i}^{j}(t)$ denotes the hiding location of $i^{\text {th }}$ crow. Eq. (26) can be rewritten as in Eq. (27).

$$
C_{i}^{j}(t+1)=C_{i}^{j}(t)\left[1-q_{i} \times f_{i}(t)\right]+q_{i} \times f_{i}(t) \times a_{i}^{j}(t)
$$

The formulation for follower salp is shown by Eq. (28).

$$
C_{i}^{j}(t+1)=\frac{1}{2}\left(C_{i}^{j}(t)+C_{i-1}^{j}(t)\right)
$$

Eq. (28) is rearranged for determining $\mathrm{C}_{\mathrm{i}}^{\mathrm{j}}(\mathrm{t})$ as shown in Eq. (29).

$$
C_{i}^{j}(t)=2\left(C_{i}^{j}(t+1)-\frac{1}{2} C_{i-1}^{j}(t)\right)
$$

Subsequently, replace Eq. (29) in Eq. (27) to find out the updated equation for SS-CSA as shown in Eq. (30).

$$
C_{i}^{j}(t+1)=2\left(C_{i}^{j}(t+1)-\frac{1}{2} C_{i-1}^{j}(t)\right) \times\left[1-q_{i} \times f_{i}(t)\right]+q_{i} \times f_{i}(t) \times a_{i}^{j}(t)
$$

On solving Eq. (30), the solution update for the SS-CSA model is determined as shown in Eq. (31).

$$
C_{i}^{j}(t+1)=\frac{1}{2 q_{i} f_{i}(t)-1}\left\{C_{i-1}^{j}(t)\left[q_{i} f_{i}(t)-1\right]+q_{i} \times f_{i}(t) \times a_{i}^{j}(t)\right\}
$$

Step 4: Determining the optimal solution: After formulating the solution space via SS-CSA, the optimal solution is determined.

Step 5: Termination: After the attainment of maximal iteration, the optimization process gets terminated, thus offering the final best solution.

\section{Results and Discussions}

\subsection{Simulation Setup}

The optimal allocation and sizing of UPQC were implemented in MATLAB and the results were examined. Here, the analysis was carried out on IEEE 123 node system. Accordingly, the SS-CSA 
technique was evaluated over existing schemes like DE [6], GA [8], and $\mathrm{ABC}$ [7] with respect to cost analysis. Moreover, convergence analysis was carried out with $3 \mathrm{UPQC}$ for varied iterations from 0,10 , $20,30,40,50,60,70,80,90$, and 100 .

\subsection{Cost Analysis}

The cost analysis of UPQC using the SS-CSA technique is given by Fig. 3 at a load disturbance of 0.85 per unit. Accordingly, the cost attained using the SS-CSA model is demonstrated without UPQC, with single UPQC, with double UPQC and with triple UPQC. From the graphical outcomes, the cost for double UPQC has accomplished minimal cost. However, as the number of UPQC rises, the installation cost of UPQC also increases.

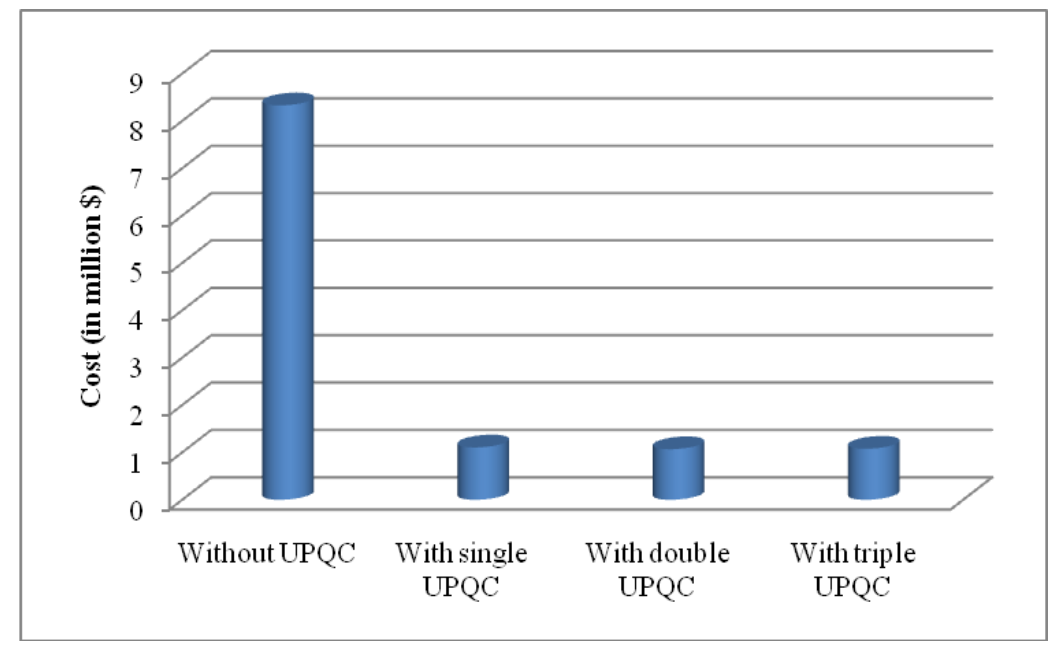

Fig. 3. Cost analysis of the adopted scheme with load disturbances of 0.85 p.u.

\subsection{Convergence Analysis}

Table 1 demonstrates the convergence analysis of cost attained by the SS-CSA scheme over diverse optimization schemes such as DE, GSA and ABC. The cost analysis was carried out in million $\$$ for 100 iterations for 3 UPQCs in IEEE 123 bus system. From the analysis, the SS-CSA scheme has attained a reduced cost function when evaluated over the existing schemes. More specifically, at $10^{\text {th }}$ iteration, the cost attained by SS-CSA scheme is $4.86 \%, 3.42 \%$, and $2.03 \%$ better than existing schemes like DE, GSA and $\mathrm{ABC}$. Thus, the enhancement of the adopted scheme has been validated effectively.

Table 1: Convergence analysis on cost with 3 UPQC for IEEE 123 test system

\begin{tabular}{lllll}
\hline Iterations & SS-CSA & DE & GSA & ABC \\
\hline $\mathbf{0}$ & 7.58 & 7.6 & 7.7 & 7.7 \\
$\mathbf{1 0}$ & 7.2 & 7.3 & 7.4 & 7.55 \\
$\mathbf{2 0}$ & 7.1 & 7.2 & 7.3 & 7.35 \\
$\mathbf{3 0}$ & 6.98 & 7.18 & 7.1 & 7.27 \\
$\mathbf{4 0}$ & 6.98 & 7 & 6.99 & 7 \\
$\mathbf{5 0}$ & 6.98 & 7 & 6.98 & 6.99 \\
$\mathbf{6 0}$ & 6.98 & 7 & 6.98 & 6.99 \\
$\mathbf{7 0}$ & 6.98 & 6.99 & 6.98 & 6.98 \\
$\mathbf{8 0}$ & 6.98 & 6.98 & 6.98 & 6.98 \\
$\mathbf{9 0}$ & 6.98 & 6.98 & 6.98 & 6.98 \\
$\mathbf{1 0 0}$ & 6.98 & 6.98 & 6.98 & 6.98 \\
\hline
\end{tabular}

\section{Conclusion}

This paper has presented an enhanced PQ system that considered the optimal sizing and placement of UPQC. For accomplishing this, SS-CSA was exploited that determined the optimal placement and sizing of UPQC optimally. In the end, the analysis was performed that substantiated the efficiency of the presented work. From the examination, the SS-CSA scheme has attained a reduced cost function when evaluated over the existing schemes. More specifically, at $10^{\text {th }}$ iteration, the cost attained by SS-CSA 
scheme was $4.86 \%, 3.42 \%$, and $2.03 \%$ better than existing schemes like DE, GSA, and ABC. Thus, the exploited model was proved over other existing models.

\section{References}

[1] Majid Moazzami, Mohammad JavadMorshed and AfefFekih, " A new optimal unified power flow controller placement and load shedding coordination approach using the Hybrid Imperialist Competitive AlgorithmPattern Search method for voltage collapse prevention in power system", International Journal of Electrical Power \& Energy Systems, vol. 79, pp. 263-274, 2016.

[2] Jayanti Sarker and S.K. Goswami, "Optimal Location of Unified Power Quality Conditioner in Distribution System for Power Quality Improvement", Electrical Power and Energy Systems, vol. 83, pp. 309-324, 2016.

[3] S. Lakshmi and S. Ganguly, "Simultaneous optimisation of photovoltaic hosting capacity and energy loss of radial distribution networks with open unified power quality conditioner allocation," IET Renewable Power Generation, vol. 12, no. 12, pp. 1382-1389, 2018.

[4] S. Ganguly, "Unified power quality conditioner allocation for reactive power compensation of radial distribution networks," IET Generation, Transmission \& Distribution, vol. 8, no. 8, pp. 1418-1429, $82014 .$.

[5] S. Ganguly, "Multi-Objective Planning for Reactive Power Compensation of Radial Distribution Networks With Unified Power Quality Conditioner Allocation Using Particle Swarm Optimization," IEEE Transactions on Power Systems, vol. 29, no. 4, pp. 1801-1810, July 2014.

[6] Guohua Wu, Xin Shen, Haifeng Li, Huangke Chen, P.N. Suganthan, "Ensemble of differential evolution variants”, Information Sciences, vol. 423, pp. 172-186, January 2018.

[7] Mustafa Servet Kıran, Oğuz Fındık, "A directed artificial bee colony algorithm”, Applied Soft Computing, vol. 26, pp. 454-462, January 2015.

[8] John McCall, "Genetic algorithms for modelling and optimisation", Journal of Computational and Applied Mathematics, vol. 184, no. 1, pp. 205-222, 1 December 2005.

[9] Swathi, R., Srinivas, A. "An Improved Image Registration Method Using E-SIFT Feature Descriptor with Hybrid Optimization Algorithm”, J Indian Soc Remote Sens, vol. 48, pp. 215-226, 2020

[10] Sanjib Ganguly, "Impact of Unified Power-Quality Conditioner Allocation on Line Loading, Losses, and Voltage Stability of Radial Distribution Systems", IEEE Transactions on Power Delivery, May 22, 2014

[11] B. Vijay Kumara, N.V. Srikanth, "A hybrid approach for optimal location and capacity of UPFC to improve the dynamic stability of the power system", Indian Department of Electrical Engineering, 21 September 2016.

[12] Susanta Dutta, Provas Kumar Roy, Debashis Nandi, "Optimal location of UPFC controller in transmission network using hybrid chemical reaction optimization algorithm", Electrical Power and Energy Systems, vol. 64, pp. 194-211, 2015.

[13] B. Karanki, N. Geddada, M. K. Mishra and B. K. Kumar, "A Modified Three-Phase Four-Wire UPQC Topology With Reduced DC-Link Voltage Rating," IEEE Transactions on Industrial Electronics, vol. 60, no. 9, pp. 35553566, Sept. 2013.

[14] V. Khadkikar, "Enhancing Electric Power Quality Using UPQC: A Comprehensive Overview," IEEE Transactions on Power Electronics, vol. 27, no. 5, pp. 2284-2297, May 2012

[15] F. Correa Monteiro, M. Aredes, J. G. Pinto, B. F. Exposto and J. L. Afonso, "Control algorithms based on the active and non-active currents for a UPQC without series transformers," IET Power Electronics, vol. 9, no. 9, pp. 1985-1994, 7272016. 